\title{
Presentación
}

\section{El cuento en revistas literarias colombianas (1900-1951). Aportes a una historia del género}

Ana María Agudelo Ochoa ${ }^{1}$

[en] Presentation. The tale in Colombian literary magazines (1900-1951). Contributions to a gender history

Cómo citar: Agudelo Ochoa, Ana María. (2018) Presentación. El cuento en revistas literarias colombianas (1900-1951). Aportes a una historia del género, en Anales de Literatura Hispanoamericana 47, 13-16.

Los estudios sobre el cuento colombianos han privilegiado el libro como fuente de análisis —básicamente volúmenes de cuento y colecciones y antologías- y la figura del autor o algunos cuentos canonizados como rutas de comprensión del estado del género en periodos específicos del sistema literario. ${ }^{2}$ El gráfico 1 representa la cantidad de primeras ediciones de libros de cuento publicados en Colombia a lo largo del siglo XX: ${ }^{3}$

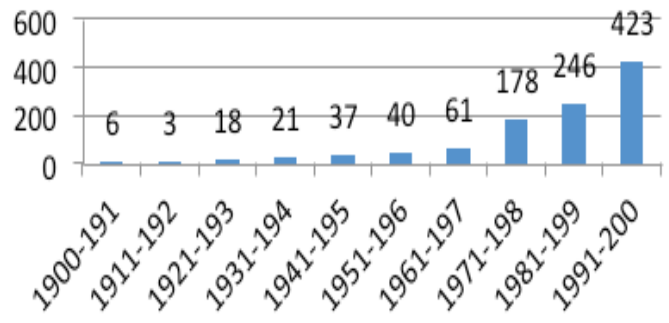

1 Universidad de Antioquia, Medellín. Colombia.

E-mail: amaria.agudelo@udea.edu.co

2 En otros países del ámbito latinoamericano la cuentística ha sido objeto de diversidad de aproximaciones de este tipo. No me es posible detenerme detalladamente en esta amplia bibliografía, pero los invito a visitar www.cuentohispanoamericano.com, un sitio que alberga información de gran interés al respecto, producto de un proyecto liderado por Juana Martínez Gómez (de la Universidad Complutense), el cual contó con la participación de investigadores de ambos lados del Atlántico. Yo misma me he concentrado en tales fuentes en mi interés por aportar al estudio histórico del cuento de mi país (en la web que antes les referí es posible encontrar algunos resultados de estas iniciativas).

3 Gráfico elaborado a partir de la información obtenida en el proyecto "Fuentes para una historia del cuento hispanoamericano del siglo XX”, centrado en la revisión de primeras ediciones de libros de cuento. 
Gráfico 1. Número de libros de cuento publicados por década en Colombia (primeras ediciones) [tomado de Agudelo (2015)]

Si nos atenemos únicamente a esta información, tendríamos que indicar que la circulación del género fue mínima: tan solo 85 libros de cuento — primeras ediciones- en el transcurso de 50 años. Cabe aclarar que calificamos como “mínima” esta producción al compararla con los más de 600 títulos de novela o los más de 1000 de poesía editados durante el mismo periodo (Agudelo 2015). Al desatender otras fuentes y perspectivas de estudio se ha omitido rastros valiosísimos para la comprensión histórica de la evolución del cuento en Colombia. Un caso concreto es el de los impresos periódicos. Una vez se dirige el foco hacia estos, el panorama cambia radicalmente y se verifica ${ }^{4}$ la vitalidad del cuento a lo largo de la primera mitad del siglo XX. No se pretende desconocer empresas de rescate de cuento publicado en periódicos y revistas, como la de los profesores Dora Helena Tamayo y Hernán Botero, Inicios de una literatura regional, o El relato en Antioquia de Jorge Alberto Naranjo, por dar solo un par de ejemplos, pero es indudable que adolecemos de análisis exhaustivos que además de emprender acciones de rescate de obras olvidadas, atiendan la singular interacción del género con su materialidad periodística.

Con el fin de aportar al estudio de este fenómeno, presentamos a continuación algunos resultados de una investigación que se concentró en 28 revistas literarias puestas en circulación en Colombia entre 1900 y 1951: "El cuento colombiano en las revistas literarias colombianas (1900-1950). Estudio histórico y hemerográfico". ${ }^{5}$ Esta investigación fue adelantada por un equipo de académicos y estudiantes, quienes se enfrentaron, en principio, a la delimitación del corpus de revistas y, posteriormente, a la revisión y descripción de las mismas, asimismo al diligenciamiento de bases de datos diseñadas por el colectivo de trabajo. Las observaciones y reflexiones que se proponen en este artículo se basan en la información obtenida gracias al trabajo conjunto. ${ }^{6}$

La "Bibliografía" del artículo "Cuento y géneros próximos en revistas literarias colombianas (1900-1951): un balance”, de Ana María Agudelo Ochoa, incluye la

4 Anteriores investigaciones desarrolladas por el grupo Colombia: tradiciones de la palabra nos han permitido constatar el protagonismo de la prensa ya desde la emergencia del sistema literario colombiano durante el siglo XIX. Puede parecer una verdad de perogrullo, pero fue necesario revisar las fuentes primarias no solo para confirmar tal lugar protagónico sino también para comprobar el caudal y significación de los “testimonios en prensa” de las dinámicas literarias y para elaborar una base datos que concentrara información de los títulos publicados entre 1835 y 1950.

5 La trayectoria del grupo de investigación Colombia: tradiciones de la palabra en el trabajo con fuentes periódicas ha permitido establecer un listado de 784 periódicos y revistas literarios (puestos en circulación entre 1835 y 1970), sistematizados en una base de datos que venimos construyendo desde el año 2012. Ante la magnitud del acervo, durante la etapa de diseño del proyecto que nos ocupa delimitamos un corpus de 28 revistas de este universo como objeto de revisión y punto de partida para nuestro estudio históricohemerográfico del cuento en Colombia; dejamos de lado, por lo pronto, periódicos y suplementos materiales que, sin duda, tendrán que ser revisados en futuros proyectos-

6 El equipo de investigación está conformado por: Paula Andrea Marín Colorado (Instituto Caro y Cuervo), Diana Paola Guzmán (Universidad Jorge Tadeo Lozano), Ana María Agudelo Ochoa (Universidad de Antioquia), Gustavo Adolfo Bedoya (Universidad de Antioquia), Diana Carolina Toro (Universidad de Antioquia), Diana Barrios (Universidad de Antioquia), Danilo Penagos J. (Universidad de Antioquia), Sara Cardona (Universidad de Antioquia), Almary Gutiérrez (Universidad de Antioquia). 
información del corpus de revistas analizado en el proceso de investigación. La revisión de la versión original de las revista fue una prioridad, no obstante en algunos casos no fue posible acceder a estos materiales. Examinamos, por lo tanto, diferentes soportes de las publicaciones: versiones originales, versiones microfilmadas, versiones facsimilares, versiones digitales y transcripciones. ${ }^{7}$

Nuestra perspectiva de estudio histórico del cuento, y de los géneros próximos, privilegia la revista en tanto espacio de emergencia, legitimación, formación de un público lector y de un mercado. La sintaxis de la revista abre una ventana a las discusiones activas en el presente de su circulación al ofrecer información acerca de la postura, argumentos y cuestionamientos del grupo tras el impreso, de las polémicas y apuestas estéticas de los grupos intelectuales que las lideraron; la disposición de los diferentes textos que coexisten número a número en una publicación conforman una trama de discursos que otorga a cada texto un sentido singular (Sarlo 1992). La singularidad de la revista literaria — su nivel de especialización, su apertura e invitación a la reflexión, su mayor vigencia en comparación con otros impresos periódicos- nos llevó a preferirla en principio como objeto de análisis. Asimismo su papel en tanto nodo, punto de cruce de una red intelectual, cuyo análisis permitirá detectar fenómenos y agentes implicados en las dinámicas del cuento colombiano. Como bien señala Claudio Maíz: "[las revistas] no sólo permiten el registro de un momento de la cultura a través de los debates, difusión de estéticas, divulgación de autores extranjeros, traducciones, en fin, el clima intelectual imperante, sino que además pueden ser vistas como ejes de religación 0 , dicho en otros términos, como redes". ${ }^{8}$

El equipo de investigadores asociado al proyecto diseñó una base de datos en la cual cada uno consignó información puntual de la(s) publicación(es) a su cargo. ${ }^{9}$ Del total de entradas que compendia la base datos, 6434 corresponden a textos que hemos clasificado como cuentos o géneros próximos. ${ }^{10}$ Las entradas restantes

7 Las bibliotecas y centros de documentación donde reposan las fuentes revisadas son la Biblioteca Carlos Gaviria Díaz (Universidad de Antioquia), Biblioteca Pública Piloto (Medellín), Biblioteca Nacional de Colombia (Bogotá), Biblioteca Luis Ángel Arango (Medellín), la Biblioteca Zea (Museo de Antioquia, Medellín), Biblioteca Luis Echavarría Villegas (Eafit). Es necesario advertir que en algunos casos fue imposible ubicar una colección completa de la publicación (es el caso de Crónica, por ejemplo).

$8 \quad$ Y continúa: "Estas redes no están compuestas nada más que por las publicaciones en sí, esto es, un conjunto de revistas que comparten más o menos ideales similares y que aparecen en etapas coetáneas, sino también que a través de ellas es posible dilucidar las densidades de los movimientos estéticos [...] Las revistas periódicas, vistas como un laboratorio, nos permiten acceder a un estado sincrónico de la cultura: discursos dominantes, prestigios construidos, ideologías en funcionamiento, campos de interés, etc. Pero pocas veces se ha señalado el papel de enlace que han ejercido entre los colaboradores" (Las re(d)vistas latinoamericanas y las tramas culturales: Redes de difusión en el romanticismo y el modernismo, en línea, https://dialnet.unirioja.es/servlet/articulo?codigo=4028310 2011).

9 La base de datos registra la siguiente información: título de la revista, título del cuento, fecha de aparición del cuento, ejemplar(es) donde aparece el cuento, autor, seudónimo, nacionalidad, existencia de dedicatoria, género asignado al texto por la publicación, género asignado al texto por el investigador (en caso de que la revista no lo indique), sección de la revista donde aparece el texto, aparición de ilustraciones que acompañen el texto, indicios acerca del estatuto del cuento en el sistema literario de la época (concursos, premios, reseñas de libros, textos críticos sobre el género, entre otros) y páginas. Algunos de estos datos están claramente incluidos en las revistas, otros deben ser completados por los investigadores, por ejemplo la nacionalidad de los autor.

10 En caso de que un cuento se publique varias veces, cada una de las apariciones se cuenta como una entrada. Asimismo se considera como una entrada cada una de las entregas de un relato entregado a lo largo de varios números de una revista. 
corresponden a reflexiones y comentarios sobre el género y demás indicios sobre el estatuto del género: convocatorias de concursos y premios, reseñas de obras, reseñas de cuentistas, indicios acerca de las relaciones entre las publicaciones periódicas, entre otros.

La información recabada gracias a la revisión del corpus sugirió temas y problemas que se abordan en los seis capítulos que conforman esta sección monográfica. El equipo de investigadores a cargo de la misma confía en que los lectores encontrarán aportes que ofrezcan nuevas vías de interpretación del sistema literario colombiano, y por extensión del hispanoamericano. Asimismo, espera sugerir nuevos cuestionamientos y brindar las bases para futuros estudios.

\section{Referencias bibliográficas}

Agudelo Ochoa, Ana María, "Hacia una historia del cuento colombiano”, Inti. Revista de Literatura Hispánica, v. 81-82 (2015), pp. 147-169.

- “Avatares de la narrativa breve en la prensa decimonónica colombiana”, en Colombia Anagramas. Rumbos y Sentidos de la Comunicación. Medellín: Sello Editorial Universidad de Medellín, v. 11, fasc. 21, 2012, pp. 61-74.

Maíz, Claudio. Las re(d)vistas latinoamericanas y las tramas culturales: redes de difusión en el romanticismo y el modernismo. Disponible en:

https://dialnet.unirioja.es/servlet/articulo?codigo=4028310 2011. 